\title{
CONTROLE EXTERNO, AUDITORIA E COMBATE À CORRUPÇÃO NO TRIBUNAL DE CONTAS DO ESTADO DO RIO GRANDE DO SUL: UMA ANÁLISE DE ÂMBITO MUNICIPAL
}

\author{
Hemerson Luiz Pase* \\ Leonardo Ferreira" \\ Paulo Ricardo Ceni Barreto \\ Sergio Luis Allebrant \\ Ana Paula Patella*
}

\begin{abstract}
RESUMO
Este artigo busca identificar e analisar fatores que retiram efetividade dos trabalhos de auditoria de regularidade do Tribunal de Contas do Estado do Rio Grande do Sul (TCERS) no cumprimento da sua missão institucional de controle externo, realizados em âmbito municipal. A pesquisa foi de natureza qualitativa e a metodologia utilizou entrevistas semiestruturadas, análise documental e revisão bibliográfica. Os achados foram apreciados à luz da análise de conteúdo, por meio de categorias. Os resultados apontaram que a efetividade é afetada em todas as categorias investigadas, cabendo esforços para o aperfeiçoamento das auditorias em relação a tecnologias de deteç̧ão e punição na seara do combate à corrupção.
\end{abstract}

PALAVRAS-CHAVE: administração pública; corrupção; controle externo; auditoria; efetividade.

* Doutor em Ciência Política (2006). Atualmente é professor e pesquisador da Faculdade de Direito da Universidade Federal do Rio Grande (FURG). Membro da Associação Brasileira de Ciência Política (ABCP) e da Associação Latino Americana de Ciência Política (ALACIP).

** Mestre em Desenvolvimento Regional.

*** Mestre em Engenharia da Produção

${ }^{* * * * *}$ Doutor em Desenvolvimento Regional

Mestra em Direito e Justiça Social. 


\begin{abstract}
This article seek to identify and to analyze factors that diminish the effectiveness of regularity auditing procedures at Tribunal de Contas do Estado do Rio Grande do Sul (TCERS) [Court of Audit of the State of Rio Grande do Sul, Brazil] within the fulfillment of its institutional mission of providing external control, conducted in the municipal scope. The research was qualitative, and the methodology used semi-structured interviews, document analysis, and literature review. The findings were assessed based on content analysis, through categories. The results showed that the effectiveness is affected in all categories under investigation, requiring efforts to perfect the audits in relation to detection technologies and punishment in the field of fight against corruption.
\end{abstract}

KEYWORDS: public administration; corruption; external control; audit; effectiveness.

\title{
INTRODUÇÃO
}

Este artigo busca identificar e analisar fatores que retiram efetividade dos trabalhos de auditoria do Tribunal de Contas do Estado do Rio Grande do Sul (TCERS) no cumprimento da sua missão institucional, realizados no âmbito municipal. Os Tribunais de Contas prestam funções de controle da administração pública, detêm matriz constitucional e competências capazes de interagir e modificar o curso das gestões auditadas (Brasil, 2013).

A auditoria pública de regularidade, uma espécie do gênero auditoria, é o exame e a avaliação da escrita contábil, dos atos e fatos da gestão, e das operações que afetam o patrimônio público. Apura o cumprimento das disposições legais e regulamentares, a probidade e a correção das decisões adotadas pelo auditado (TCERS, 2013). A Figura 1 ilustra o tema. 
FIGURA 1 - Delimitação do tema de identificação do objeto

Controle externo constitucional da administração pública brasileira (arts. 31 e 70 a 75 )

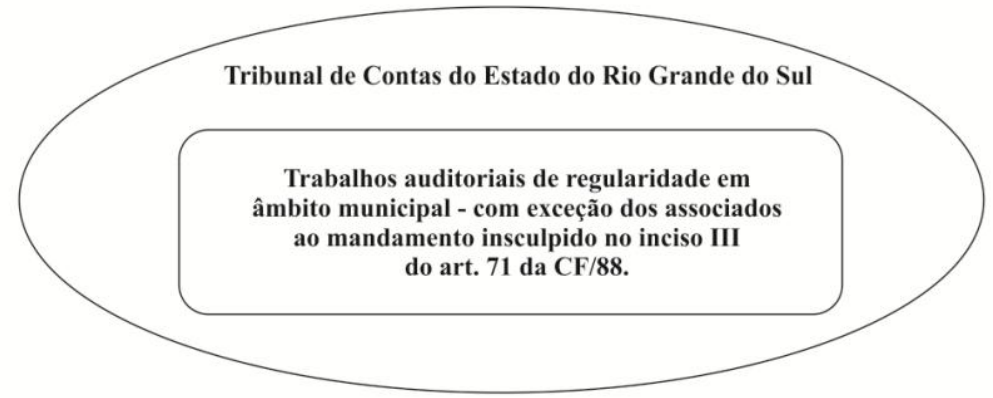

FONTE: elaborada pelos autores.

A escolha pela esfera municipal foi movida pela importância dos municípios no desenvolvimento socioeconômico e político do país. Após a Constituição de 1988, eles passaram a assumir cada vez mais o papel de welfare, com crescentes gastos públicos (Allebrandt, 2002). Nesse esforço, utilizaram-se as contribuições da Nova Economia Institucional (NEI) ${ }^{1}$. North (1990; 1991; 2005; 2006) constrói uma análise econômica considerando o ser humano como detentor de uma racionalidade limitada. Ou seja, é importante observar as suas limitações diante da complexidade do mundo. A construção analítica parte também da compreensão de que sem instituições não há intercâmbio e demais dinâmicas sociais propiciadoras de desenvolvimento (North, 1990). E sobre a adequada interpretação do termo instituições, North (1991:97) as define como "the humanly devised constraints that structure political, economic and social interaction. They consist of both informal constraints (sanctions, taboos, customs, traditions, and codes of conduct), and formal rules (constitutions, laws, property rights)".

Instituições são as regras formais e informais, os vetores de estímulos para os diversos atores sociais. Como exemplo, têm-se as regras eleitorais, os direitos de propriedade e o direito contratual

${ }^{1}$ Principalmente o core teórico produzido por Douglass North (Nobel em 1993), Ronald Coase (Nobel em 1991), Oliver Williamson e, mais recentemente, Daron Acemoglu e James Robinson. Os pesquisadores defendem argumentos valendo-se de análises históricas e econométricas. 
(Williamson, 1993). Outro ponto teórico da análise são as organizações, os jogadores (North, 2005:22), que são compostas de grupos de indivíduos que propugnam por objetivos comuns. Elas podem ser econômicas, políticas, educacionais ou de natureza diversa. As organizações nascem do ambiente institucional e são condicionadas pelas regras (North, 2006). Coase (1937) entende custos de transação como aqueles incorridos para além dos custos de produção. Eles envolvem busca e coleta de informações, barganhas, incertezas, assim como custos de monitoramento dos ajustes. Esses elementos transacionais são condicionados à matriz institucional.

Portanto, desvelar a efetividade dos trabalhos auditoriais do TCERS e o papel deste como organização de combate à corrupção é o fim buscado pelo trabalho. Para Aguiar (2010), as cortes de contas garantem que os recursos confiados pelo cidadão ao Estado serão utilizados dentro da lei, de forma escorreita, eficiente, eficaz e em benefício de todos. Esses mecanismos estão contidos no conceito de enforcement - sistema de sanções que promove a observância às regras. North (1990:54) chega a assentar que "the inability of societies to develop effective, low-cost enforcement of contracts is the most important source of both historical stagnation and contemporary underdevelopment in the Third World".

$\mathrm{O}$ senso de irresponsabilização propicia facilidades ao indivíduo para extrapolar a busca legítima de seus interesses, passando à trapaça. Williamson (1985) definiu essa perspectiva como oportunismo, uma busca por interesses particulares em detrimento do interesse alheio. Ambientes de oportunismos e de baixo grau de enforcement são ilustrados por North (2005:23), quando observa que "if the highest rate of return in an economy comes from piracy we can expect that the organizations will invest in skills and knowledge that will make them better pirates". Para a NEI, a maturidade das instituições de uma nação é mais importante do que, por exemplo, as descobertas tecnológicas e os recursos naturais. Então a pergunta que guiou o trabalho foi: existem fatores que retiram efetividade dos trabalhos de auditoria de regularidade do TCERS no cumprimento da sua missão institucional, realizados no âmbito municipal? A problemática a ser enveredada é oriunda de inquietações que desacreditam os trabalhos realizados pelas cortes de contas, conforme elenca o Quadro 1: 
QUADRO 1 - Críticas que desacreditam os trabalhos

Consideramos, com base na experiência de nossos países, que estes controles são inaptos para produzir mudança de mentalidade, de atitudes, de comportamentos e crenças; ao contrário, podem estar retroalimentando o sistema coadjuvando a crescente regulamentação da atividade pública, realçando a formalidade em detrimento da eficácia (Gordillo, 1981:79).

Como foi observado no caso de Ribeirão Bonito, o Tribunal de Contas do Estado tende a verificar somente os aspectos formais das despesas. $\mathrm{O}$ órgão fiscalizador não entra no mérito se a nota fiscal contabilizada é "fria" ou não, se a empresa é "fantasma" ou não, se o valor é compatível com o serviço ou não, e se o procedimento licitatório foi montado e conduzido adequadamente ou não. O Tribunal só examina tais questões quando estimulado especificamente. Contudo, mesmo que os aspectos formais examinados sejam irrelevantes diante da grosseira falsificação de documentos verificada em muitas prefeituras do país, os Tribunais de Contas mantêm os seus procedimentos. [...] Na forma como atua hoje, os Tribunais de Contas não contribuem significativamente para o fim da corrupção. (Trevisan et al., 2003:23).

[...] é flagrante que parcelas significativas dos desvios de recursos públicos registrados no Brasil, seja por desperdício ou fraudes, podem ser atribuídas ainda à ineficácia dos órgãos de controle existentes. [...] Os Tribunais de Contas, por exemplo, responsáveis pelo Controle Externo, não obstante alguns esforços recentes, não têm sido, através do tempo, uma grande referência enquanto órgãos capazes de evitar ou minimizar o número de ocorrências de desvios. (Ribeiro, 2004:120).

Em suma, no Brasil, o exercício da Auditoria Governamental, na atualidade, encontra sérias barreiras à eficácia da mesma [...] (Sá, 2007:14-15).

Aos habituais reclamos referentes a falhas na atuação dos Tribunais de Contas para impedir o mau uso dos recursos públicos, o que responder? Pregar a abolição da entidade? Transformá-la em órgão singular, como nos Estados Unidos e Inglaterra? Como propiciar aprimoramento da sua atuação para melhor preservação dos recursos públicos e para que a função de controle realmente se realize? (Medauar, 2012:146).

FONTE: elaborado pelos autores com base nas referências.

Como esposado, os relatos de insatisfação com as ações de controle externo e auditoria governamental vêm de muitos pesquisadores. Para outros, afiguram-se como instituições importantes para o desenvolvimento socioeconômico e para o 
combate à corrupção (Brown Ribeiro, 2002; Aguiar, 2010; Mileski, 2011; Fernandes, 2012).

\section{METODOLOGIA}

Pela natureza e pela finalidade dos resultados esperados, temse aqui uma pesquisa aplicada (Gil, 2008), na medida em que se tem fundamental interesse na utilização e nas consequências do conhecimento. Do ponto de vista da perspectiva investigativa, é uma pesquisa qualitativa, atribuindo-se importante papel à interpretação (Gil, 2008). Minayo (2012) explica que a pesquisa qualitativa, nas ciências sociais, ocupa-se com um nível de realidade que não pode ou não deveria ser quantificado. $O$ universo de organizações envolvidas na pesquisa mantém relação direta ou indireta com o serviço prestado pelo TCERS, conforme o Quadro 2.

QUADRO 2 - Organizações relevantes para o estudo

\begin{tabular}{|c|}
\hline Tribunal de Contas do Estado do Rio Grande do Sul (TCERS) \\
\hline Tribunal de Contas da União (TCU) \\
\hline Supremo Tribunal Federal (STF) \\
\hline Superior Tribunal de Justiça (STJ) \\
\hline Tribunal de Justiça do Estado do Rio Grande do Sul (TJRS) \\
\hline Controladoria-Geral da União (CGU) \\
\hline Ministério Público do Estado do Rio Grande do Sul (MPRS) \\
\hline Polícia Civil do Estado do Rio Grande do Sul (PCRS) \\
\hline
\end{tabular}

FONTE: elaborado pelos autores.

Interagiram na construção agentes públicos que atuam, de alguma forma, no controle da administração pública. A seleção considerou a relação da atividade profissional com o tema, a acessibilidade e a aceitação dos partícipes. Foram entrevistados operadores de controle do TCERS, do MPRS, do TCU e da PCRS. Interagiram 3 (três) auditores do TCERS, 1 (um) auditor do TCU, 1 (um) delegado de Polícia Civil, 2 (dois) promotores de justiça do MPRS e um juiz de contas do TCERS. As entrevistas ocorreram durante o primeiro semestre de 2014.

Efetuou-se um inventário dos convênios firmados pelo TCERS com outras organizações. A pesquisa também analisou relatórios de 
auditoria da área municipal ${ }^{2}$ a partir de 2004. As amostras selecionadas não adotaram critérios probabilísticos, deram-se por acessibilidade ou conveniência (Minayo, 2012). Utilizou-se a análise de conteúdo como plano de interpretação (Bardin, 2011). Assim, o trabalho foi arranjado em categorias temáticas. O Quadro 3 apresenta as categorias e subcategorias:

QUADRO 3 - Categorias e subcategorias

\begin{tabular}{|c|c|}
\hline Categorias de análise & Subcategorias de análise \\
\hline $\begin{array}{c}1 \text { - Trabalhos auditoriais e } \\
\text { segurança jurídica }\end{array}$ & $\begin{array}{c}1.1 \text { - Imputação de responsabilidade } \\
\text { pelos atos e fatos da gestão } \\
1.2-\text { Qualidade das provas angariadas } \\
\text { pela auditoria }\end{array}$ \\
\hline $\begin{array}{c}2 \text { - Trabalhos auditoriais e } \\
\text { combate à corrupção }\end{array}$ & $\begin{array}{c}2.1 \text { - Interpretação acerca da missão } \\
\text { institucional do TCERS } \\
2.2-\text { Trabalhos auditoriais e combate à } \\
\text { corrupção }\end{array}$ \\
\hline
\end{tabular}

FONTE: elaborado pelos autores.

A subcategoria 1.1 condensou uma investigação sobre como a auditoria de regularidade encara a responsabilidade pelos atos e fatos da gestão fiscalizada. Já a subcategoria 1.2 voltou o olhar para a qualidade das provas colacionadas pelos trabalhos. A subcategoria 2.1 foi destacada para apurar se a missão institucional paira com clareza entre os operadores do controle externo, enquanto a subcategoria 2.2 buscou verificar se os trabalhos, de âmbito municipal, combatem a corrupção que envolve os fiscalizados.

Para o TCU (2010), a efetividade é a avaliação dos impactos concernentes à atuação da organização no cumprimento da missão institucional, ficando em segundo plano os custos. Bergue (2014) defende que o controle externo efetivo é o que a sociedade precisa e quer - numa expressão essencialmente política. Entende controle externo efetivo como o que causa impacto transformador positivo. Coelho (2010), por sua vez, entende o controle externo efetivo como aquele que cumpre a sua missão: fiscalizar a arrecadação e a aplicação dos recursos públicos.

${ }^{2}$ Foram analisados 37 (trinta e sete) trabalhos de auditoria obtidos por meio da Lei de Acesso à Informação. 


\section{CONTROLE EXTERNO E AUDITORIA DA ADMINISTRAÇÃO PÚBLICA}

Os controles ligados à administração pública são ínsitos às formas mais tenras de Estado. Brown Ribeiro (2002) relata registros de controle e de fiscalização já na unificação dos dois Egitos, em 3200 a.C. Segundo Medauar (2012), controle é a verificação da conformidade de uma atuação a determinados cânones. Em sentido lato, poder-se-ia entender o controle externo da administração pública como aquele praticado pelo Poder Judiciário, pelo Ministério Público, pelos parlamentos - não necessariamente o controle sobre os fatos contábeis, econômicos e financeiros, stricto sensu. Para os fins propostos, controle externo "é o que se realiza por órgão estranho à Administração responsável pelo ato controlado e visa a comprovar a probidade da Administração e a regularidade da guarda e do emprego dos bens, valores e dinheiros públicos, bem como a fiel execução do orçamento" (Henrique Lima, 2011:8).

Na maioria dos países existe um órgão incumbido desse controle. Eles se valem da técnica de auditoria para alcançar a sua missão (Fernandes, 2012). O espectro conceitual de auditoria varia conforme a natureza da abordagem. Encontram-se elucidativas considerações lançadas pelo TCU (2011:13), baseadas em trabalhos internacionais: "é $o$ processo sistemático, documentado e independente de se avaliar objetivamente uma situação ou condição para determinar a extensão na qual critérios são atendidos, obter evidências quanto a esse atendimento e relatar os resultados dessa avaliação a um destinatário". Existem inúmeros procedimentos de auditoria governamental, sendo eles aplicados caso a caso. Para fins de exemplo, citam-se: análise documental, exame e comparação de registros, inspeção física, contagem, observação, circularização, recálculo, levantamentos estatísticos, correlação, entrevistas etc. (De Lima e Castro, 2003; IRB, 2011). É comum o emprego simultâneo de vários.

Foi a Revolução Francesa que indubitavelmente marcou a evolução do controle externo sobre os recursos geridos pelo Estado, quando movimentos sociais derrubaram a monarquia absolutista que governou durante séculos (Brown Ribeiro, 2002:50; Pelegrini, 2014). $\mathrm{O}$ atual modelo brasileiro teve o seu germe com a proclamação da República, em 1889. Foi por meio do Decreto n 966-A, de 07-11- 
1890, que se criou o TCU (Aguiar; Albuquerque; Medeiros, 2011). O TCERS só veio a ser criado em 26-06-1935, após o Decreto Estadual $\mathrm{n}^{\mathrm{o}} 5.975$ (TCERS, 2013). A partir de 1946, as constituições brasileiras passaram a tratar do Tribunal de Contas no capítulo destinado ao Poder Legislativo ${ }^{3}$ (Pelegrini, 2014), tendo o termo "controle externo" surgido pela primeira vez na Carta de 1967 (Aguiar, 2010).

Modernamente, é premente apartar as cortes de contas do modelo clássico montesquiano de divisão tripartite do poder estatal. Ocorre que o enquadramento constitucional do controle externo brasileiro não está inserido no corpo orgânico de nenhum dos três poderes (Pelegrini, 2014). Para bem exercer as suas funções constitucionais, o controle externo é autônomo e independente, tanto do Legislativo quanto do Judiciário e do Executivo (Mello, 2009; Pelegrini, 2014:96).

A redação do art. 71 da Constituição de 1988 pode trazer certa confusão, já que assenta: " $O$ controle externo, a cargo do Congresso Nacional, será exercido com o auxílio do Tribunal de Contas [...]" (Brasil, 2013). A carga jurídica do verbete "auxílio" trata apenas da necessária cooperação entre os Tribunais de Contas e os Poderes Legislativos, não de uma subordinação (Ayres Britto, 2004:176-178; Mello, 2009:67; Medauar, 2012:144). As suas funções são indispensáveis ao funcionamento do Estado, representando bastiões dos direitos fundamentais (Mello, 2009; Medauar, 2012). Pelegrini (2014:92) observa que "poucas instituições possuem papel tão relevante e indispensável como aquela criada com o objetivo primordial de fiscalizar e controlar os gastos públicos".

O controle externo está encarregado da fiscalização contábil, financeira, orçamentária, operacional e patrimonial. Prestam contas qualquer pessoa física ou jurídica, pública ou privada, que administre dinheiros, bens e valores públicos. Aos Tribunais de Contas cabe emitir parecer sobre as contas dos chefes dos Executivos, julgar as contas dos administradores e demais responsáveis por bens e valores, assim como as contas daqueles que derem causa a prejuízo ao erário.

${ }^{3}$ O controle externo, desenhado pela Carta Magna, compreende dois aspectos: o político, atribuído aos órgãos do Poder Legislativo, e o técnico, exercido pelos Tribunais de Contas. Este trabalho ocupou-se dos aspectos técnicos. 
Eles apreciam a legalidade dos atos de admissão de pessoal e de concessões de aposentadorias, reformas e pensões. Realizam auditorias nas mais variadas unidades da administração, em todos os poderes. Podem aplicar aos responsáveis sanções, incluindo multa proporcional ao dano (Brasil, 2013).

Verificada ilegalidade, é competência dos Tribunais de Contas assinar prazo para que o órgão fiscalizado adote providências. Qualquer cidadão, partido político, associação ou sindicato é parte legítima para denunciar irregularidades à Corte de Contas (Brasil, 2013). Não bastassem as per si robustas competências constitucionais, outros difusos normativos lançam funções às cortes de contas, como a fiscalização da legitimidade da procedência dos bens e rendas acrescidos ao patrimônio dos agentes públicos (TCERS, 2013).

\section{O FENÔMENO CORRUPÇÃO E O TCERS}

O Banco Mundial tem a corrupção como o maior obstáculo para o desenvolvimento socioeconômico dos povos (Speck, 2000). Tal qual North (1991), entende que o fenômeno distorceria a autoridade das leis e enfraqueceria a base institucional necessária ao crescimento. A Organização para a Cooperação e Desenvolvimento Econômico (OCDE) afirma que a corrupção tem se tornado um assunto de suma importância política e econômica, sendo necessário combatê-la (Speck, 2000).

Referências à corrupção podem ser encontradas já no Código de Hamurabi (XVIII a.C.) (Ribeiro, 2004; Nunes, 2008). O fenômeno permeia países desenvolvidos e em desenvolvimento e setores públicos e privados. Reveste-se de custos transacionais e outras manifestações deletérias que não podem ser facilmente medidas (Ribeiro, 2004; CGU, 2008). Corrói a confiança da qual a democracia precisa para os cidadãos (North, 1991).

Mesmo assim, ter a corrupção como malefício na construção de sociedades nem sempre foi consenso. Segundo Carraro (2003), alguns economistas viam a corrupção como uma "graxa" capaz de lubrificar e dar eficiência às transações, constituindo-se em uma acidentalidade. Essa visão muda e a temática passa a receber volumosa atenção já a partir da segunda metade da década de 70 
(Tanzi, 1998; Nunes, 2008). Segundo Carraro (2003), a partir da década de 90 vastas referências à corrupção são identificadas em um grande número de revistas internacionais, como Corruption and Reform, Journal of Law and Society e European Journal of Political Economy. Segundo Avritzer e Filgueiras (2011), 73\% dos brasileiros consideram a corrupção como muito grave e $24 \%$ como grave $-97 \%$ consideram-na deletéria.

Para Ribeiro (2004), a palavra corrupção tem origem no vocábulo latino corruptione, significando decomposição, putrefação e suborno ${ }^{4}$. Para este artigo, fica-se com as conclusões de Tanzi (1998:8), para quem a corrupção é difícil de ser descrita, mas não difícil de ser reconhecida - infelizmente, é muitas vezes difícil de ser observada, já que não acontece à luz do dia; e de Becker (1968) e Rose-Ackerman (1999), segundo os quais a corrupção se dá por uma escolha racional entre custos e benefícios.

Para Nunes (2008), o fenômeno da corrupção nas sociedades mais desenvolvidas tende a ser raro e isolado, enquanto nas sociedades menos desenvolvidas passa a ser sistêmico e recorrente conclusão que corrobora o fraco enforcement diagnosticado pela NEI em sociedades subdesenvolvidas.

Em 31 de outubro de 2003, a Organização das Nações Unidas (ONU) aprovou a convenção contra a corrupção - United Nations Convention Agaisnt Corruption (UNCAC) ${ }^{5}$. A UNCAC trouxe uma série de medidas a serem seguidas pelos países signatários no sentido de garantir uma estrutura institucional adequada ao trato da corrupção, entre elas implementação da criminalização e efetiva aplicação da lei, cooperação internacional, recuperação de ativos e incentivo à participação da sociedade (CGU, 2008). A Convenção almeja um Estado promotor dos valores éticos, como integridade, honestidade e transparência, cujo modelo cobre alto nível de profissionalismo, capacidade técnica e independência dos servidores públicos.

\footnotetext{
4 Do prisma semântico, Machado (2010), utilizando o Domínio Semântico de Determinação (DSD), chegou a bons resultados.

5 Além da convenção da ONU, o Brasil também é signatário da convenção interamericana contra a corrupção da Organização dos Estados Americanos (OEA)(CGU, 2008).
} 
Após o definhamento do regime militar em $1985^{6}$ e a subsequente redemocratização vivida no Brasil, os casos de corrupção viraram cotidianos. Veio a queda da censura e a liberdade à informação (Carraro, 2003; Ribeiro, 2004). A partir do estudo de Avritzer e Filgueiras (2011), é possível elencar uma síntese de casos de corrupção após o impeachment de Fernando Collor: caso Antônio Magri, Anões do Orçamento, escândalo dos precatórios, máfia das propinas, caso Marka/FonteCindam, Tribunal Regional de SP, caso Sudam, Vampiros, operação Sanguessugas e Mensalão. É possível, ainda, apresentar casos relevantes de corrupção no trabalho de Ribeiro (2004): cestas da LBA, máfia da Previdência, compra de votos para a reeleição, Hildebrando Pascoal e máfia dos bingos. Identificam-se, com base em casos concretos, os que furtam por meio de obras, de eventos, de serviços de qualificação profissional, de emendas parlamentares, de ONGs, dos contratos de publicidade e de consultorias.

Só no ano de 2013, foram recebidas mais de 8.000 (oito mil) denúncias pelo TCERS (2013). No período de 2009 a 2013, o TCERS (2013) consumiu $\mathrm{R} \$ 1.516 .848 .623,23$ para efetivar a sua missão constitucional (institucional). Assim, é necessário que se demonstre que a medida entre o ganho advindo da corrupção e o risco de sanção não compensa.

\section{TRABALHOS DE AUDITORIA E SEGURANÇA JURÍDICA}

As decisões dos Tribunais de Contas são objeto de discussão no Judiciário, porque o monopólio de jurisdição foi entregue a este (inciso $\mathrm{XXXV}$, art. 5 da CF/88) (Brasil, 2013). Como exemplo empírico anotado no Rio Grande do Sul, tem-se o acórdão n 70052113081 do TJRS $^{7}$. O julgado entendeu que a regra é descaber o reexame pelo Poder Judiciário quanto às decisões do TCERS, mas ressalvou casos de manifesta ilegalidade, desconstituindo então a decisão criticada. Outro exemplo da intervenção é o acórdão $n^{\circ}$ 70041123399. O STF e o STJ têm frequentemente apreciado imputações definidas pelo TCU; em

\footnotetext{
${ }^{6}$ Para leitura de relatos de casos de corrupção no Brasil no período de 1980 a 1988 , ver Bezerra (1995).

${ }^{7}$ Os julgados citados estão disponíveis nos sites dos Tribunais.
} 
muitas confirmam a decisão da Corte de Contas, quando a mesma não detém vícios: mandados de segurança $\mathrm{n}^{\mathrm{os}} 25.460 / \mathrm{DF}$ e $25.880 / \mathrm{DF}$, do $\mathrm{STF}$, e agravo regimental no recurso especial $\mathrm{n}^{\circ} 1.252 .142 / \mathrm{RJ}$ e recurso especial $\mathrm{n}^{\circ}$ 1.032.732/CE, do STJ.

Sobre processo nos Tribunais de Contas, Amorim (2006) argumenta que o sistema é muitas vezes inconstitucional, havendo necessidade de lei nacional. Ayres Britto (2004) e Gracie (2007) entendem que cabe revisão integral pelo Poder Judiciário das decisões desses tribunais. Gracie (2007:8) concluiu que os processos mantidos pelas cortes de contas devem observar os princípios e as garantias do processo judicial, como o contraditório e a ampla defesa, provas lícitas, duração razoável e adequada fundamentação, tudo isso em processo público. Há vozes minoritárias que dissentem na questão. Citam uma decisão de 1967 do STF, onde salvo nulidade decorrente de irregularidade formal grave ou manifesta ilegalidade, é do Tribunal de Contas a competência exclusiva para julgamento das contas dos responsáveis (Mileski, 2011; Fernandes, 2012:150).

A possibilidade de revisão das decisões das cortes de contas pelo Poder Judiciário é tese que se solidificou.

\subsection{Imputação de responsabilidade pelos atos e fatos}

Apurou-se que os trabalhos auditoriais do TCERS não discutem a responsabilidade pelos atos e fatos da gestão fiscalizada. A quase totalidade dos trabalhos objetiva a responsabilidade na figura do prefeito (ou do chefe maior da organização). Os trabalhos não têm como responsabilidade civil subjetiva o dano ao erário ou mesmo as meras irregularidades administrativas achadas, contrariando o $\$ 6^{\circ}$ do art. 37 da CF/88 (Brasil, 2013). Essa prática tem origem no Regimento Interno do TCERS, em seu art. 139, onde "é pessoal a responsabilidade do administrador relativamente aos atos e fatos de sua gestão", só afastada em caso de tomada de contas especial (TCERS, 2017a). Todos os 37 (trinta e sete) trabalhos auditoriais obtidos chamam aos autos apenas o prefeito ou o chefe maior da auditada (Legislativo, autarquias, fundações). Nenhum agente público de outra hierarquia, ou mesmo privado, foi responsabilizado. As entrevistas realizadas com agentes do TCERS vão no mesmo sentido. O Quadro 4 ilustra: 
QUADRO 4 - Respostas à imputação de responsabilidade

\begin{tabular}{|c|l|}
\hline Entrevistado & \multicolumn{1}{|c|}{ Excerto da fala } \\
\hline Juiz de contas & $\begin{array}{l}\text { Nós temos aqui uma tradição, diria até antiga, de concentrar } \\
\text { responsabilidade no dirigente maior daquela estrutura [...] }\end{array}$ \\
\hline Auditor 1 & $\begin{array}{l}\text { A responsabilidade é do gestor independente do que } \\
\text { ocorra. No caso das prefeituras o prefeito, o presidente da } \\
\text { câmara, o presidente ou o diretor geral executivo do órgão. }\end{array}$ \\
\hline Auditor 2 & $\begin{array}{l}\text { A responsabilidade é atribuída especificamente ao gestor } \\
\text { [...] fragiliza o processo, principalmente se for recorrer ao } \\
\text { judiciário. }\end{array}$ \\
\hline Auditor 3 & $\begin{array}{l}\text { Esse processo está mudando. Com os novos normativos que } \\
\text { o TCE está editando, haverá responsabilização do agente } \\
\text { público, não só do agente político. }\end{array}$ \\
\hline
\end{tabular}

FONTE: elaborado pelos autores a partir das entrevistas.

A análise do conteúdo da fala do juiz entrevistado demonstra preocupação com a questão, referindo que o assunto é "debatido muito". O auditor 3 informa que normativos em edição irão permitir a responsabilização de outros. $\mathrm{O}$ auditor 2 coloca que fica um clima de irresponsabilização entre os demais. Já o conteúdo da fala dos 3 (três) auditores entrevistados demonstra que a questão precisa ser revista. Infere-se que não está na práxis dos auditores discutir a conduta dos diversos agentes em suas fiscalizações e imputar responsabilidades a partir dela.

No MPRS, um promotor de justiça, ao tomar conhecimento da pergunta no mesmo sentido, manifestou-se: "Assim, eu vou buscar a condenação de todos, tu entende? Pelas circunstâncias [...], pelas peculiaridades do caso". E demonstrou surpresa ao ser informado que no TCERS a práxis é diferente: "É o prefeito, ele não vai ver lá se foi o secretário, se foi o presidente da comissão de licitação?". O acórdão $\mathrm{n}^{\mathrm{o}}$ 70016495806 do TJRS deixa claro que a responsabilidade pessoal dos agentes pelos danos ao erário é de natureza subjetiva, o que exige o dolo ou a culpa. O TCU tem a responsabilidade pelos atos e fatos como subjetiva, discutindo os casos por meio de uma matriz de responsabilidades. Um auditor do TCU explica que "a partir daí tem uma matriz de responsabilização [...] Quem é que foi o responsável por aquele ato irregular? Foi o Reitor, foi o presidente da comissão, todos os membros da comissão, a pessoa que fez o edital?’”. 


\subsection{Qualidade das provas angariadas pela auditoria}

A Constituição de 1988 anota: “aos litigantes, em processo judicial ou administrativo, e aos acusados em geral são assegurados o contraditório e a ampla defesa, com os meios a ela inerentes" inciso LV do art. $5^{\circ}$ (Brasil, 2013). No âmbito do processo judicial, as partes têm o direito de empregar todos os meios legais, bem como os meios moralmente legítimos, ainda que não especificados pela lei, para provar a verdade dos fatos em que se funda a ação ou a defesa e influir eficazmente na convicção do juiz. Apenas as provas ilegais não são aceitas.

Ocorre que as provas angariadas pelos auditores são documentais, por regra. São notas de empenho, contratos, processos licitatórios, contracheques, não constando nos trabalhos provas testemunhais, captações de áudio e gravações em vídeo, entre outras. O desfecho do processo $n^{\circ} 104 / 1.10 .0000206-8$ do TJRS demonstra um caso em que o emprego de todos os meios de prova admitidos pelo direito, incluindo-se provas testemunhais (não aceitas pelo TCERS), acabou por elidir responsabilidades imputadas ao fiscalizado pelo TCERS.

Auditores do TCERS elucidaram que "nunca fiz e não vi ninguém fazer também" (filmagens), "as provas são basicamente documentais" (tipos de provas), "não vi essa prática e acho que se houver algum tipo de [...] acho que não existe nenhum obstáculo, contudo, não existe uma cultura pra isso e também não existe nenhum tipo de treinamento" (oitivas de agentes), "não fui treinado pra obter prova, as nossas provas são basicamente documentais" (treinamento), "eu acho que a gente pode evoluir e evoluir muito" (sobre provas).

Não há treinamento para a obtenção de provas, não são efetuadas oitivas de testemunhas, não são captados sons ambientais ou realizadas filmagens. Um juiz de contas expressou que "em tese me parece possível" (filmagens), mas que "não deve fazer parte da nossa rotina de fiscalização", isso porque "parece ter muito mais haver com uma prática policial ou do próprio Ministério Público". Revelou, assim, certa resistência ao implemento de novas técnicas e testes.

Inventariaram-se convênios firmados pelo TCERS com outras organizações, visando o aperfeiçoamento do controle. Esse trabalho 
foi desenvolvido por unidade do TCERS criada com finalidade precípua de subsidiar trabalhos de auditoria. Com essas medidas, infere-se que o TCERS busca avançar na necessária coleta de informações para subsidiar os trabalhos de auditoria.

Mesmo assim, apurou-se que a efetivação desses esforços não alcançou a plenitude. Um auditor, em exercício de fiscalizações, consignou: "os auditores de campo têm acesso ao banco de dados do DETRAN e da Junta Comercial, através de um colega no serviço regional. Os demais convênios são acessados de forma ainda mais indireta [...] não existe nenhum trabalho difundido de consolidação $e$ cruzamento das informações disponibilizadas através dos convênios [...] não foi fornecido nenhum tipo de treinamento [...] não se sabe exatamente que tipo de informação temos". Conforme a fala, a interação entre a unidade estratégica do TCERS e os auditores não foi otimizada. Esses fatores, como o subaproveitamento de meios e técnicas legalmente viáveis para a ação fiscalizatória, retiram efetividade dos trabalhos.

\section{TRABALHOS AUDITORIAIS E COMBATE À CORRUPÇÃO}

É importante apurar se (1) o TCERS é uma organização de assessoria, consultoria, ensino e aprendizagem de administração pública ou se seus esforços são verdadeiramente focados no controle, fiscalização, auditagem e correição das transações econômicas e financeiras ocorridas na seara pública. São linhas distintas e não se confundem, embora complementares. A primeira emprega uma percepção de ação didático-pedagógica, dialogal. A outra, uma ação de correição, restritiva de direitos. Os ditames institucionais impõem às funções do TCERS o segundo papel. Funcionar diferente retira efetividade. E também cumpre apurar se (2) os trabalhos empreendidos são os mais profícuos na detecção (descoberta) e na punição (responsabilização) da corrupção. As Figuras 2 e 3 ajudam na exposição. 
FIGURA 2 - Matriz institucional e organizações.

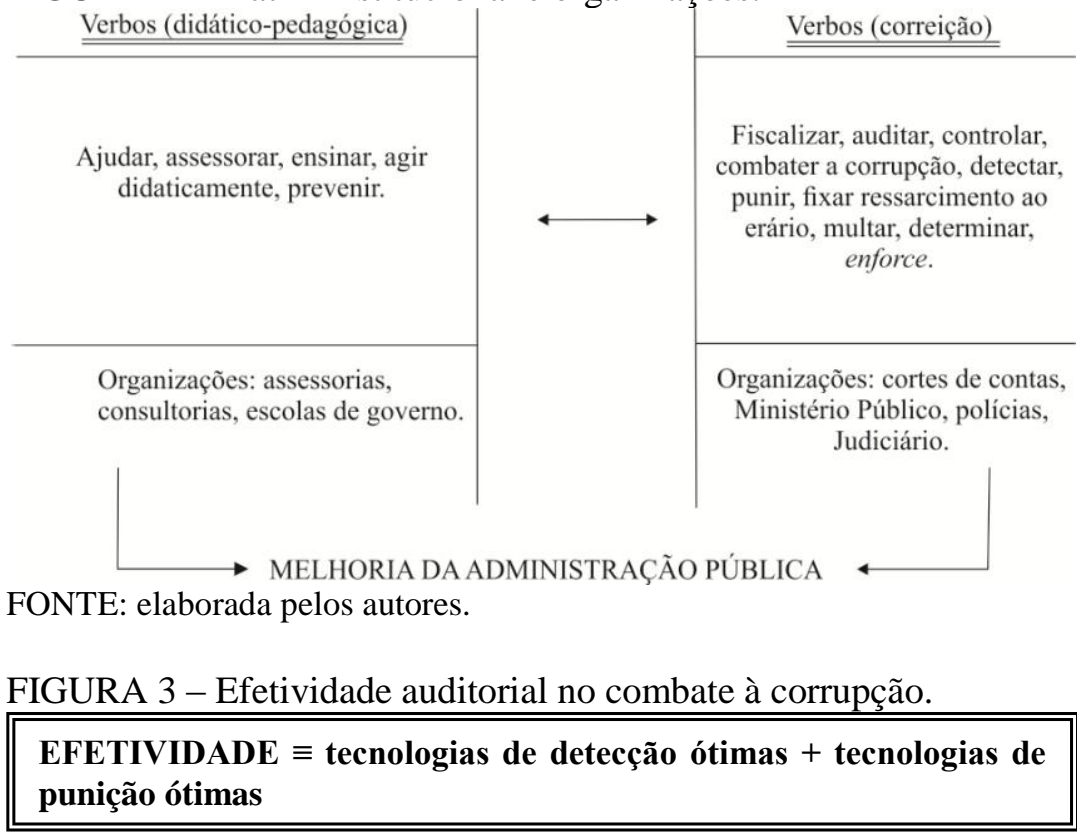

FONTE: elaborada pelos autores.

Seguem as últimas subcategorias.

\subsection{Interpretação acerca da missão institucional do TCERS}

Esta subcategoria apurou se a missão institucional (constitucional) do TCERS está bem compreendida entre os operadores e se a organização foca os seus esforços nela. Um juiz de contas entrevistado argumentou que "essas funções não são excludentes e, embora a função orientadora-pedagógica [...] não tenha acento expresso na constituição, ela não colide com a chamada Lei Maior”. A mensagem emitida aponta como aceitável uma missão didático-pedagógica para o TCERS, muito embora essa função não conste no rol de competências. A crítica para esse discurso, ressalvados os reflexos positivos, é o descolamento da missão constitucional expressa dos Tribunais de Contas e o enfraquecimento das energias dedicadas ao combate à corrupção. $\mathrm{O}$ 
mesmo entrevistado usou a expressão "não deve ser a forma principal de atuação nossa" (filmagens), quando colocado hipoteticamente em um caso. Observou-se uma contradição na argumentação do juiz, porque ao ser questionado sobre a importância da Corte no combate à corrupção, disse ver o órgão estatal como absolutamente relevante.

Um auditor do TCU citou, na linha do magistrado, outras instituições para isso, como a Polícia, o Ministério Público e a CGU. O esposado pelos dois agentes não condiz com a construção constitucional dos Tribunais de Contas e corrobora as críticas. A força dada para essa tese pedagógica retira esforços do cumprimento da missão institucional, do enforcement entregue às cortes de contas. Sobre isso, Coelho (2010:67) lembra que a efetividade do controle não se confunde com a efetividade das políticas públicas.

Um auditor do TCERS reforça traços de path dependence nessa interação. Entende que "acho que a atividade educação é uma atividade secundária [...] o Tribunal tem agido de uma maneira que fornece instrução ao longo do tempo e isso já vem de muito". Outro auditor foi enfático: "acho que qualquer esforço despendido no sentido de deixar de atuar no controle para atuar de outra forma deve ser deixado de lado".

\subsection{Trabalhos de auditoria e combate à corrupção}

Conforme um filme de Hollywood, o ex-presidente americano Abraham Lincoln praticou atos corruptos visando determinados fins. Trocou favores, comprou votos e fez chantagens. Como resultado, obteve o reconhecimento de direitos humanos para pessoas negras, o fim da guerra civil e um recomeço para os Estados Unidos. Cientes do filme, entrevistados foram colocados diante da questão: são aceitáveis atos de corrupção se for possível sopesar as vantagens coletivas advindas?

Os entrevistados foram unânimes em rechaçar a corrupção. As respostas trouxeram colocações como: "Não. Eu acredito que não [...] por mais que se procure dar essa justificativa de um futuro melhor para a sociedade"; "Definitivamente, não"; "Não são aceitáveis"; "eu acho que não, eu não concordo"; "Não, acho que em hipótese alguma"; "Eu não tenho como aceitar". A fala de um 
dos entrevistados foi mais reflexiva. Colocou: "eu nunca me deparei com um ato de corrupção que possuísse essas finalidades [...]". E, após, consignou: "um ato de corrupção, hoje, pode levar à derrocada desse regime democrático. Não acho que, por exemplo, o Mensalão se justifique". Entre os agentes de controle, nenhuma forma corruptiva foi aceita.

Faccioni (2008) argumenta assim: ruim com os Tribunais de Contas, "pior sem eles". Explica que os Tribunais não têm legitimidade para executar suas decisões e para a quebra de sigilo bancário e fiscal. Informa que lei processual, para uniformizar os procedimentos, e a criação do Conselho Nacional dos Tribunais de Contas são importantes. O senso de fiscalização colocado por Faccioni (2008) não foi considerado pela análise, porque a presença de uma ação fiscalizatória, mesmo inefetiva, tende a propiciar ação de enforcement contrária à corrupção. Essas foram as conclusões de Avis, Ferraz e Finan (2016). A análise ora proposta tencionou ir além. Uma vez existentes no mandamento constitucional, são eles o mais efetivo possível na detecção e na punição da corrupção?

O TCERS firmou o I Pacto Republicano de Estado pela Promoção dos Direitos Humanos Fundamentais e Enfrentamento à Corrupção e um acordo de cooperação com diversos órgãos do Rio Grande do Sul, visando articular fiscalizações de combate à corrupção (iniciativa do TCU) (TCERS, 2013). Porém, observou-se baixo grau de interação dos auditores com outras organizações. Quando defrontados com a afirmação de que é "fundamental a construção de uma cultura institucional que envolva a quebra do isolamento", as respostas apontaram que "isso não é importante só para o Tribunal de Contas. É importante para os outros órgãos também. [...] Acaba perdendo muito do seu poder de combate à corrupção por esse isolamento" - auditor, com 5 (cinco) anos de experiência; "Historicamente todas as instituições. Se tu considerar a administração pública em geral, em relação ao executivo [...] Eu acho que a questão é muito relevante" - auditor, com 18 (dezoito) anos de experiência. Lançada a questão: "nesse período, você já interagiu efetivamente com outros órgãos?", obteve-se: "efetivamente, com operação em conjunto, nunca" - auditor, com 5 (cinco) anos de experiência; "Eu até nem tenho ideia, não conheço nenhuma [...]" - auditor, com 18 (dezoito) anos de experiência. O 
primeiro ponderou que "a nossa área é administrativa, a gente infere e verifica muitas vezes a corrupção. Nesse sentido, sim. Agora, em conjunto nunca, no máximo troca de informações".

Quando o auditor mais experiente questionado se (1) os motivos eram culturais e perpassavam a hierarquia ou se (2) também os auditores não interagiam por características pessoais, obtemperou que as duas coisas ocorriam. Extrai-se que a interação entre órgãos é fundamental e essa medida não cabe apenas ao TCERS; cabe também aos outros organismos. No combate, imperiosa é a interação com outras instituições (Bergue, 2014).

Observaram-se baixas tecnologias de punição. Dentre as sanções aplicadas pelo TCU, identificam-se a inabilitação para o exercício de cargos públicos, o poder cautelar de indisponibilidade de bens, o afastamento temporário do responsável fiscalizado, a declaração de inidoneidade para licitar com a administração pública federal e a multa proporcional ao dano - isso inclui setor privado. Essas medidas não são aplicadas pelo TCERS (TCERS, 2014; Brasil, 2017). A multa máxima por infrações é de apenas $R \$ 1.500,00$. Pode constar um número expressivo de irregularidades que a multa máxima será de R \$1.500,00. E o TCERS não responsabiliza pessoas ou organizações privadas.

Quando o TCERS emite parecer desfavorável às contas de um prefeito ou julga irregulares as contas de um dirigente máximo de um órgão fiscalizado, incluindo-se aí os Legislativos municipais, o efeito político não é imediato. Para que seja decretada a propagada inelegibilidade, é necessário ter, para além das contas rejeitadas, a configuração de ato doloso de improbidade administrativa - esse trâmite é da Justiça Eleitoral. Outra fragilidade é a não oferta ativa dos relatórios de auditoria. Um juiz de contas entrevistado esclareceu que a prática é a oferta desse documento apenas mediante pedido formalizado.

\section{CONSIDERAÇÕES FINAIS}

Por que as nações fracassam? Segundo Acemoglu e Robinson (2012), porque as instituições políticas são extrativistas (Estado desconstituído, poder ilimitado e concentrado) e não inclusivas (Estado constituído, poder limitado e plural). Elas ditam instituições 
econômicas ineficientes (extrativistas), em que as regras do jogo não estimulam os agentes a investir em atividades individuais que tragam retornos sociais maiores que os custos sociais. A solução é um sistema de regras políticas inclusivas, com direitos de propriedade claros, acompanhado de enforcement efetivo (North, 1990; Acemoglu e Robinson, 2012). Para a NEI, a corrupção corrói as regras (instituições), gerando incertezas, desestímulos e aumentando os custos de transação. É inviável um ambiente de instituições políticas inclusivas sem o combate à corrupção (North, 2003).

Os Tribunais de Contas são alvo de inúmeras críticas relacionadas à efetividade dos serviços. Um dos motivos para esse quadro de insatisfação é a baixa participação dessas organizações em notórios casos de combate à corrupção. O TCERS, enquanto organização política com competências de enforcement sobre os (des)caminhos da administração pública, possui fatores identificáveis que retiram efetividade das auditorias municipais de regularidade ao não otimizarem as tecnologias de detecção e punição.

Não se aponta lúcida a aceitação, entre os operadores, de um sistema de combate à corrupção na administração pública capitaneado pelos Tribunais de Contas, como imperativo da Carta Magna, onde a matriz institucional assume as vezes de fiscalização, auditagem, detecção, punição e policiamento. As feições didático-pedagógicas dividem o espaço e consomem a energia disponível da missão maior dessas instituições. A despeito dos efeitos positivos dessas ações didático-pedagógicas, a efetividade no combate à corrupção perde tecnologia de detecção. A ausência de interações efetivas com outras organizações de controle, como o Ministério Público e a Polícia, também enfraquece as tecnologias de detecção, do mesmo modo que a frágil operacionalização das possibilidades prometidas pelo sem número de convênios firmados e a falta de treinamento para a produção de provas. É necessário o desenvolvimento de um perfil investigativo-proativo no corpo de auditores, além de um arranjo hierárquico que não obstaculize a fluidez necessária para as tarefas. Os trabalhos precisam implementar qualidade nos elementos probatórios, realizando oitivas de testemunhas e de agentes (públicos e privados), captação de áudios, vídeos e cruzamento de informações, especialmente bancárias e fiscais.

O TCERS tem amplo poder de investigação, cabendo-lhe 
requisitar e examinar, diretamente ou através de seus auditores, a qualquer tempo, todos os elementos necessários ao exercício de suas atribuições, não podendo ser negada qualquer informação, a pretexto de sigilo $-\S \S 2^{\circ}$ e $3^{\circ}$ do art. 71 da Constituição do Estado (TCERS, 2017b). A responsabilização pelos atos e fatos irregulares deve ser pessoal, subjetiva, com a ponderação da conduta do agente. Sem essa prática, os trabalhos não só perdem efetividade punitiva como geram um senso de irresponsabilidade para os demais, que não estão no topo da hierarquia. Outra fragilidade é a ausência de (1) uma lei processual nacional, que homogeneíze os expedientes para os vários tribunais de contas; e de (2) um Conselho Nacional com competências de correição administrativa, como no Judiciário e no Ministério Público.

Acerca das tecnologias punitivas, o TCERS precisa incidir sobre os agentes privados, implementar a indisponibilidade acautelatória de bens, o afastamento de fiscalizados, a decretação de inidoneidade para contratar com a administração, a inabilitação para o exercício de cargo público e a multa proporcional ao dano causado ao erário. Sobre a multa ordinária, é recomendável o aumento da cifra (com gradações) e a aplicação por irregularidade. Também é importante a divulgação ativa na rede dos relatórios auditoriais.

A efetividade do sistema fiscalizatório contribui para o grau de aderência às normas formais e informais da democracia, sendo um dos quesitos essenciais ao desenvolvimento socioeconômico de uma nação no longo prazo.

\section{REFERÊNCIAS}

ACEMOGLU, Daron; ROBINSON, James A. Why nations fail: the origins of power, prosperity, and poverty. New York: Crown Business, 2012.

AGUIAR, Ubiratan D. de. Tribunal de Contas da União: auxílio indispensável no combate à corrupção na administração pública. Revista de informação legislativa, n. 187, p. 301-319, jul./set., 2010.

, Ubiratan D. de; ALBUQUERQUE, Marcio André Santos de;

MEDEIROS, Paulo Henrique Ramos. A administração pública sob a perspectiva do controle externo. Belo Horizonte: Fórum, 2011.

ALLEBRANDT, Sérgio Luís. A participação da sociedade na gestão pública. Ijuí: UNIJUÍ, 2002.

AMORIM, Aderbal T. de. A inconstitucionalidade do sistema processual 
dos Tribunais de Contas: uma proposta de lei nacional. Revista de processo, São Paulo, n. 142, p. 106-113, dez. 2006.

AVIS, Eric; FERRAZ, Claudio; FINAN, Frederico. Do government audits reduce corruption? Estimating the impacts of exposing corrupt politicians. Cambridge: NBER, 2016. (Texto para Discussão n. 22443). Disponível em: $<$ http://www.nber.org/papers/w22443 $>$. Acesso em: 19 fev. 2017.

AVRITZER, Leonardo; FILGUEIRAS, Fernando. Corrupção e controles democráticos no Brasil. Brasília: CEPAL-IPEA, 2011.

AYRES BRITTO, Carlos. O regime constitucional dos Tribunais de Contas. In: SOUZA, Alfredo José de et al. O novo Tribunal de Contas: órgão protetor dos direitos fundamentais. 2. ed. Belo Horizonte: Fórum, 2004. p. 175-191.

BARDIN, Laurence. Análise de conteúdo. São Paulo: Edições 70, 2011.

BECKER, Gary S. Crime and punishment: an economic approach. Jornal of Political Economy, v. 76, n. 2, p.169-217, 1968.

BERGUE, Sandro T. Tribunais de Contas e controle externo: estratégia e carreiras de Estado no contexto contemporâneo. Achados de auditoria, n. 3, p. 12-13, jun. 2014.

BEZERRA, Marcos Otávio. Corrupção: um estudo sobre poder público e relações pessoais no Brasil. São Paulo: ANPOCS, 1995.

BRASIL. Constituição da República Federativa do Brasil, de 5 de outubro de $1988 . \quad$ Disponível em: <http://www.planalto.gov.br/ccivil_03/Constituicao/Constituicao.htm>. Acesso em: 10 out. 2013.

. Lei n. 8.443, de 16 de julho de 1992. Disponível em: <http://www.planalto.gov.br/ccivil_03/Leis/L8443.htm〉. Acesso em: $17 \mathrm{fev}$. 2017.

BROWN RIBEIRO, Renato Jorge. Controle externo da administração pública federal no Brasil. Rio de Janeiro: América Jurídica, 2002.

CARRARO, André. Um modelo de equilíbrio geral computável com corrupção para o Brasil. 2003. 194f. Tese (Doutorado em Economia) Programa de Pós-Graduação em Economia, Universidade Federal do Rio Grande do Sul, Porto Alegre, 2003.

CGU. Controladoria Geral da União. Convenção das Nações Unidas contra a corrupção. Brasília: CGU, 2008.

COASE, Ronald H. The nature of the firm. Economica, v. 4, p. 386-405, nov. 1937.

COELHO, Hamilton Antônio. O papel dos Tribunais de Contas na busca da 
efetividade do controle externo. Revista TCEMG, Belo Horizonte, n. 2, v. 75, p. 66-76, abr.-jun. 2010.

DE LIMA, Diana V.; CASTRO, Róbison G. de. Fundamentos de auditoria governamental e empresarial. São Paulo: Atlas, 2003.

FACCIONI, Victor José. Pior sem eles... Zero Hora, Porto Alegre, 10 jul. 2008. Opinião.

FERNANDES, Jorge Ulisses J. Tribunais de Contas do Brasil. 3. ed. Belo Horizonte: Fórum, 2012.

GIL, Antônio Carlos. Métodos e técnicas de pesquisa social. 6.ed. São Paulo: Atlas, 2008.

GORDILLO, Augustín. Problemas del control de la administración pública en América Latina. Madrid: Civitas, 1981.

GRACIE, Ellen. Notas sobre a revisão judicial das decisões do Tribunal de Contas da União pelo Supremo Tribunal Federal. Revista do TCU, p. 7-14, set./dez. 2007.

HENRIQUE LIMA, Luiz. Controle externo. 4. ed. Rio de Janeiro: Elsevier, 2011.

IRB. Instituto Rui Barbosa. Normas de auditoria governamental. Tocantins: IRB, 2011.

MACHADO, Julio Cezar. Um estudo semântico enunciativo da corrupção em dicionários e documentos governamentais. Alfa, São Paulo, v. 54, n. 1, p. 145-175, 2010.

MEDAUAR, Odete. Controle da administração pública. 2. ed. São Paulo: Revista dos Tribunais, 2012.

MELLO, Celso Antônio B. de. O enquadramento constitucional do Tribunal de Contas. In: FREITAS, Ney José de (Coord.). Tribunais de Contas: aspectos polêmicos: estudos em homenagem ao Conselheiro João Féder. Belo Horizonte: Fórum, 2009. p. 63-72.

MILESKI, Helio S. O controle da gestão pública. 2. ed. Belo Horizonte: Fórum, 2011.

MINAYO, Maria Cecília de S. (Org.). Pesquisa social: teoria, método e criatividade. 32. ed. Petrópolis: Vozes, 2012.

NORTH, Douglass C. Institutions, institutional change and economic performance. New York: Cambridge University Press, 1990.

, Douglass C. Institutions. Journal of Economic Perspectives, v. 5, n. 1, p. 97-112, 1991. 
, Douglass C. Para um país enriquecer. Veja, São Paulo, n. 1830, 26 nov. 2003. Entrevista concedida a Monica Weinberg.

, Douglass C. Institutions and the performance of the economies over time. In: MÉNARD, C.; SHIRLEY, Mary M. Handbook of new institutional economics. Dordrecht: Springer, 2005.

, Douglass C. Custos de transação, instituições e desempenho econômico. Rio de Janeiro: Instituto Liberal, 2006.

NUNES, Antonio Carlos O. Corrupção: o combate através da prevenção. In: PIRES, Luis Manuel Fonseca; ZOCKUN, Maurício; ADRI, Renata Porto (Coord.). Corrupção, ética e moralidade administrativa. Belo Horizonte: Fórum, 2008. p. 15-35.

PELEGRINI, Marcia. A competência sancionatória do Tribunal de Contas: contornos constitucionais. Belo Horizonte: Fórum, 2014.

RIBEIRO, Antonio S. M. Corrupção e controle na administração pública brasileira. São Paulo: Atlas, 2004.

ROSE-ACKERMAN, Susan. Corruption and government: causes, consequences, and reform. Cambridge: Cambridge University Press, 1999.

SÁ, Antônio L. de. Prefácio. In: CRUZ, Flávio da. Auditoria governamental. 3. ed. São Paulo: Atlas, 2007.

SPECK, Bruno W. Mensurando a corrupção: uma revisão de dados provenientes de pesquisas empíricas. São Paulo: Fundação Konrad Adenauer, 2000.

TANZI, Vito. Corruption around the World: causes, consequences, scope, and cures. Working Paper of the International Monetary Fund, mai. 1998.

TCERS. Tribunal de Contas do Estado do Rio Grande do Sul. Portal, s/l, s/d. Disponível em: <http://www1.tce.rs.gov.br/portal/page/portal/tcers/>. Acesso em: 18 out. 2013.

. Tribunal de Contas do Estado do Rio Grande do Sul. Lei Estadual n. 11.424, de 6 de janeiro de 2000. Disponível em: <http://www1.tce.rs.gov.br/portal/page/portal/tcers/consultas/legislacoes/ato s_normativos_tcers/lei_organica>. Acesso em: 30 ago. 2014.

. Tribunal de Contas do Estado do Rio Grande do Sul. Resolução n. 1028, de 4 de março de 2015. Disponível em: <http://www1.tce.rs.gov.br/portal/page/portal/tcers/consultas/legislacoes/ato s_normativos_tcers $>$. Acesso em: $16 \mathrm{fev}$. 2017a.

Estadual.

. Tribunal de Contas do Estado do Rio Grande do Sul. Constituição Disponível em: 
<http://www1.tce.rs.gov.br/portal/page/portal/tcers/consultas/legislacoes>. Acesso em: 16 fev. $2017 \mathrm{~b}$.

TCU. Tribunal de Contas da União. Técnica de indicadores de desempenho para auditorias. Brasília: TCU, 2010. Disponível em: <http://portal2.tcu.gov.br/portal/page/portal/TCU/comunidades/programas_ governo/tecnicas_anop/BTCU_indicadores_de_desempenho.pdf $>$. Acesso em: 9 dez. 2013.

Tribunal de Contas da União. Normas de auditoria. Brasília: TCU, $2011 . \quad$ Disponível em: <http://portal2.tcu.gov.br/portal/page/portal/TCUcomunidades/fiscalizacao_ controle/normas_auditoria>. Acesso em: 22 out. 2013.

TREVISAN, Antoninho M. et al. O combate à corrupção nas prefeituras do Brasil. 2. ed. Cotia: Ateliê Editorial, 2003.

WILLIAMSON, Oliver E. The economic institutions of capitalism: firms, markets, relational contracting. New York: The Free Press, 1985.

Oliver E. Transaction cost economics and organization theory. Industrial and corporate change, v. 2, n. 2, p. 107-156, 1993. 